\title{
Acute Promyelocytic Leukemia: 37 Years Long Ongoing Survival in a de novo Patient with Metal-Based Ayurvedic Treatment
}

\author{
Balendu Prakash ${ }^{1}$ Shikha Prakash ${ }^{2}$ Sneha Tiwari ${ }^{3}$ \\ ${ }^{1}$ Research Division, VCPC Research Foundation, Rudrapur, \\ Uttarakhand, India \\ 2Department of Medicine, Padaav-Speciality Ayurvedic Treatment \\ Centre, Dehradun, Uttarakhand, India \\ ${ }^{3}$ Department of Clinical Research, VCPC Research Foundation, \\ Rudrapur, Uttarakhand, India
}

\begin{abstract}
Address for correspondence Balendu Prakash, BAMS, Research Division, VCPC Research Foundation, Prakash Villa, Beside Rave Cinemas, Danpur, Rudrapur 263153, Uttarakhand, India (e-mail: balenduprakash@gmail.com).
\end{abstract}

\begin{abstract}
Acute promyelocytic leukemia (APML) is a subtype of acute myeloid leukemia. The condition is clinically marked by anemia, fatigue, weakness, frequent infections, and fever associated with easy bleeding and coagulopathy. The diagnosis is made through bone marrow aspiration exhibiting increased promyelocytes and test for PML-RARa fusion gene. There has been remarkable progress in the treatment of APML in the past few decades with the induction of all-trans retinoic acid (ATRA) and arsenic trioxide (ATO). This has also brought down mortality and relapse rates considerably. Similarly, nearly $90 \%$ patients are able to live disease free for about 10 years. However, there are certain hindrances to these treatments majorly due to side effects, relapses, and limited periods of remission associated with ATRA and ATO. Here, a freshly diagnosed case of APML is being reported. The patient was diagnosed in leading medical centers

Keywords

- APML

- ayurveda

- blood transfusions of Aligarh and New Delhi and only treated with blood transfusions in the absence of an established line of treatment in 1982. The patient has completed 37 years long survival without any sign of the disease and any adverse effect. This approach could be considered as an add-on medical therapy for APML.
\end{abstract}

A 10-year-old boy was admitted in the outdoor patient unit of Jawaharlal Nehru Medical College, Aligarh (OPD No. C-17891/82) with symptoms of high fever, hematuria, nasal bleeding, and pallor. He was diagnosed with acute promyelocytic leukemia (APL) using blood picture dated December 2, 1982 (hemoglobin: 8 g\%, total leukocyte count: $2,100 / \mathrm{mm}^{3}$, blast: $8 \%$, promyelocytes: $23 \%$, myelocytes: $2 \%$, polymorphs: 60 , and platelets: $15,000 / \mathrm{mm}^{3}$ ). He was treated with intravenous fluids, frequent blood transfusions, antibiotics, and antipyretic medicines and was referred to the then Department of Hematology, All India Institute of Medical Sciences, New Delhi for further management (Ref No. 54092) where his prognosis was declared to be poor. His family contacted Meerut-based doctor (Ayurvedacharya), Late Vaidya Chandra Prakash, who administered his self-prepared silver-based Ayurvedic compound, called Navjeevan, $250 \mathrm{mg}$ thrice a day with $60-\mathrm{mL}$ mixture of extracts of rose, sandalwood, and gojihwa. ${ }^{1,2}$ All conventional treatments along with blood transfusions were stopped at the commencement of Ayurvedic treatment. Within 3 hours of the consumption of the Ayurvedic formulation, bleeding stopped. The boy was given ice cap therapy to bring down the fever. He was kept in complete isolation and given a balanced diet with more dairy products. Consumption of tea and coffee was stopped. He received complete hematological remission after 6 weeks of Ayurvedic treatment. Details of blood tests are presented in -Table 1.
DOI https://doi.org/

10.1055/s-0040-1715765

ISSN 2454-6798.
License terms

(1) (1) $\odot \circledast$ 
Table 1 Results of blood tests conducted

\begin{tabular}{|c|c|c|c|c|c|}
\hline & Date & $\mathrm{Hb}(\mathrm{g} \%)$ & TLC (/mm3) & Platelets (/mm3) & Immature cells \\
\hline \multirow{3}{*}{ Pretreatment } & December 02, 1982 & 8 & 2,100 & Inadequate $(15,000)$ & $\begin{array}{l}\text { 33\% (Blasts: } 8 \% \text {, Promyelocytes: } \\
\text { 23\%, Myelocytes: } 2 \% \text { ) }\end{array}$ \\
\hline & December 15, 1982 & 10.5 & 5,650 & Inadequate & $\begin{array}{l}\text { 64\% (Promyelocytes: 61\%, } \\
\text { Myelocytes: 3\%) }\end{array}$ \\
\hline & December 21, 1982 & 12.5 & 6,650 & Inadequate & $\begin{array}{l}\text { 42\% (Blasts: } 1 \% \text {, Promyelocytes: } \\
\text { 40\%, Myelocytes: } 1 \% \text { ) }\end{array}$ \\
\hline \multirow{3}{*}{ Post-treatment } & December 27, 1982 & 8.5 & 800 & Inadequate $(21,000)$ & - \\
\hline & November 21, 1983 & 11 & 8,500 & Adequate & \\
\hline & November 02, 2019 & 15 & 6,300 & Adequate $(2,88,000)$ & \\
\hline
\end{tabular}

Abbreviations: Hb, hemoglobin; TLC, total leukocyte count.

Since then, all his reports and other biochemical parameters remained within normal limits. No adverse effects were seen. The boy is a grown-up man now who lives in Dubai with his family and two children and has completed 37 years of overall survival (duration of complete remission: 36 years).

APML or AML M3 is characterized by an arrest of leukocyte differentiation at the promyelocyte stage. It has been considered as the most malignant form of acute leukemia for decades because of severe bleeding tendency and high rate of early death, mostly due to disseminated intravascular coagulation or hyperfibrinolysis. ${ }^{3}$ Earlier studies indicate a median survival of less than 1 week, ranging from 1 week to 1 month in APML cases, when patients remained untreated or received corticosteroids along with whole blood transfusions. ${ }^{4}$ Great progress has been made in the last three decades in the treatment of APML with the intervention of all-trans retinoic acid (ATRA), arsenic trioxide (ATO), and anthracycline-based chemotherapy. Still, early deaths in freshly diagnosed cases and post-therapy relapse remain obstacles in achieving longterm survival. ${ }^{3}$ Also, adverse effects associated with conventional treatment are also a cause of concern in many cases.

In the stated background, there is scope to improve existing therapies or to develop other therapies which could further escalate the response, duration of remission, and minimize side effects. The stated case was diagnosed and treated before the introduction of ATRA and ATO when there was no established line of treatment. The patient showed quick and sustainable recovery after the administration of Ayurvedic formulation and still remains well without experiencing any adverse effect. It can easily be concluded that the stated formulation could have altered the natural history of the disease and might have brought the longest overall and disease-free survival in a de novo APML patient.

We are reporting this case with the view that the principles and formulations of Rasa Shastra in Ayurveda should be explored further in the prevention and treatment of hematopoietic disorders with more emphasis on APML. ${ }^{5}$ It is imperative to mention that this medicine has not yet been analyzed for its chemical nature and nomenclature. The dosage, duration, mode of action also needs to be understood with the help of modern scientific, biological, and pharmacological tools.

Note

B.P. has US and European patents issued for innovation and formulation in use.

\section{Conflict of Interest}

None declared.

\section{References}

1 Prakash B, Parikh PM, Pal SK. Herbo-mineral ayurvedic treatment in a high risk acute promyelocytic leukemia patient with second relapse: 12 years follow up. J Ayurveda Integr Med 2010;1(3):215-218

2 Prakash B, Prakash S, Sharma S, Tiwari S. Remission in a relapse case of acute promyelocytic leukaemia for twenty-two years using metal based ayurvedic treatment: a case report. J Ayur Case Rep. 2019;2(2):3-8

$3 \mathrm{Li} \mathrm{J}, \mathrm{Zhu} \mathrm{H}, \mathrm{Hu}$ J, et al. Progress in the treatment of acute promyelocytic leukemia: optimization and obstruction. Int J Hematol 2014;100(1):38-50

4 Coombs CC, Tavakkoli M, Tallman MS. Acute promyelocytic leukemia: where did we start, where are we now, and the future. Blood Cancer J 2015;5:e304

5 Savrikar SS, Ravishankar B. Introduction to 'Rasashaastra' the iatrochemistry of ayurveda. Afr J Tradit Complement Altern Med 2011;8(suppl 5) :66-82 